\title{
Liquid-liquid equilibria for the ternary system water + tetradecane + 2-butyloxyethanol
}

\author{
Bo-Jiun Lin, Li-Jen Chen* \\ Department of Chemical Engineering, National Taiwan University, Taipei 10617, Taiwan
}

Received 17 April 2003; accepted 5 September 2003

\begin{abstract}
Liquid-liquid equilibria of the ternary system water + tetradecane + 2-butyloxyethanol in the temperature range from 298.15 to $338.15 \mathrm{~K}$ were investigated at atmospheric pressure. The experimental data correlated well with the UNIQUAC model. For the system with a three-liquid-phase-coexisting region, all the six UNIQUAC interaction parameters can be determined numerically by minimizing the deviation of the compositions of three coexisting liquid phases only.
\end{abstract}

(C) 2003 Elsevier B.V. All rights reserved.

Keywords: Liquid-liquid equilibria; Phase equilibria; Ternary system; UNIQUAC model

\section{Introduction}

Precise liquid-liquid equilibrium data of mixtures of the type water + oil + surfactant are needed in several industrial applications, for example, herbicides, tertiary oil recovery, and the production of drugs [1,2]. Nonionic surfactants of the homologous series of polyoxyethylene alcohol $\mathrm{CH}_{3}\left(\mathrm{CH}_{2}\right)_{i-1}\left(\mathrm{OCH}_{2} \mathrm{CH}_{2}\right)_{j} \mathrm{OH}$, abbreviated by $\mathrm{C}_{i} \mathrm{E}_{j}$ hereafter, are widely used for emulsifying agents and detergents. In addition, the phase behavior of mixtures of the type water + oil $+\mathrm{C}_{i} \mathrm{E}_{j}$ also plays an important role in the fundamental work of critical phenomena, phase conductivity, and wetting transitions [3-9]. In our laboratory, recently, we have performed liquid-liquid equilibrium measurements on water $+\mathrm{C}_{i} \mathrm{E}_{j}$ binary systems [10] and five ternary systems: water + dodecane $+\mathrm{C}_{4} \mathrm{E}_{1}[11]$; water + octane $+\mathrm{C}_{4} \mathrm{E}_{2}$ [12]; water + decane $+\mathrm{C}_{4} \mathrm{E}_{2}$ [13]; water + dodecane $+\mathrm{C}_{6} \mathrm{E}_{2}$ [14]; and water + tetradecane $+\mathrm{C}_{6} \mathrm{E}_{2}$ [15].

Kilpatrick et al. [16] have studied the phase behavior of the ternary mixture water + alkane $+\mathrm{C}_{4} \mathrm{E}_{1}$ at 298.15 and $303.15 \mathrm{~K}$ for five different alkanes: hexane, octane, nonane, decane, and tetradecane. However, they reported the phase diagram of the ternary system water + tetradecane

\footnotetext{
* Corresponding author. Tel.: +886-2-23623296; fax: $+886-2-23623040$

E-mail address: 1jchen@ntu.edu.tw (L.-J. Chen).
}

+ 2-butyloxyethanol $\left(\mathrm{C}_{4} \mathrm{E}_{1}\right)$ only at $298.15 \mathrm{~K}$. In this study, liquid-liquid equilibrium measurements were preformed for the ternary system water + tetradecane $+\mathrm{C}_{4} \mathrm{E}_{1}$ in the temperature range from 298.15 to $338.15 \mathrm{~K}$ at atmospheric pressure. The experimental data were further correlated with universal quasi-chemical (UNIQUAC) model [17] to determine the effective binary interaction parameters at different temperatures.

\section{Experimental}

Tetradecane was obtained from Merck with a purity of 99\%. The nonionic surfactant 2-butyloxyethanol was an Aldrich Chemical product with a purity of $99 \%$. These two chemicals were used as received without further purification. Water was purified by a Millipore Milli-RO PLUS 10 and Milli-Q system with a resistivity $>8.2 \mathrm{M} \Omega \mathrm{cm}$.

All samples were prepared with known compositions in test tubes sealed with septum and placed in a computer controlled thermostat, whose temperature was controlled within $\pm 0.005 \mathrm{~K}$, and left at least $24 \mathrm{~h}$ for equilibration. After equilibrium was reached, each phase was analyzed with a gas chromatograph (China Chromatography 9800, Taiwan) equipped with a thermal conductivity detector. The signal was transferred to an integrator (C-R6A, Chromatopac, Shimadzu Co., Japan) to record area fractions. The tem- 
Table 1

Average deviations of calibration curves of the gas chromatograph

\begin{tabular}{lll}
\hline Binary system & Concentration $^{\mathrm{a}}$ range of $\mathrm{C}_{4} \mathrm{E}_{1}$ & Average error \\
\hline Water $+\mathrm{C}_{4} \mathrm{E}_{1}$ & $0.0238-0.0879$ & 0.0001 \\
& $0.04292-0.978$ & 0.0003 \\
Tetradecane $+\mathrm{C}_{4} \mathrm{E}_{1}$ & $0-1$ & 0.0002 \\
\hline
\end{tabular}

a Mass fraction.

b Average error $=(1 / N) \sum_{i=1}^{N}\left|W_{i}^{\text {calc }}-W_{i}^{\text {act }}\right|$, where $N$ is the number of calibration points and $W$ is the mass fraction of $\mathrm{C}_{4} \mathrm{E}_{1}$. The superscript 'calc' stands for the calculated value from the calibration curve and the superscript 'act' refers to the actual value.

peratures of the injector port and the thermal conductivity detector were held at 543.15 and $573.15 \mathrm{~K}$, respectively. The flow rate of the carrier gas, helium, was maintained at $45 \mathrm{ml} \mathrm{min}-1$. The sample was isothermally separated at $508.15 \mathrm{~K}$ in a $2 \mathrm{~m}$ long $\times 3.175 \mathrm{~mm}$ diameter stainless steel column packed with Poropak P 80/100 mesh. Each analysis took about $8 \mathrm{~min}$. Single-phase binary mixtures, water $+\mathrm{C}_{4} \mathrm{E}_{1}$ and tetradecane $+\mathrm{C}_{4} \mathrm{E}_{1}$, with known compositions were used to calibrate the instrument in the composition range of interest. The calibration results were further fitted to a polynomial equation. The average errors of the calibration curves from the actual values are given in Table 1 . For each tie line, at least three samples were prepared at the same total composition. After equilibration, at least three gas chromatograph measurements were performed for each phase in every sample. The experimental uncertainty of the gas chromatography was within \pm 0.0008 mass fraction.

When the water content in the tetradecane-rich phase was low, a Karl Fischer moisture titrator (MKC-210, Kyoto Electronics Co., Japan) was used to determine the water content in these phases. The experimental uncertainty of at least three Karl Fischer moisture measurements was within \pm 0.00002 mass fraction for the water content.

\section{Results and discussion}

The experimental compositions of the equilibrium phases of the ternary system water + dodecane $+\mathrm{C}_{4} \mathrm{E}_{1}$ at 298.15 , 308.15 , and $318.15 \mathrm{~K}$ are given in Tables $2-4$, respectively. According to Kahlweit and Strey [18], the lower critical solution temperature for the ternary system water + tetradecane $+\mathrm{C}_{4} \mathrm{E}_{1}$ is around $311.15 \mathrm{~K}$ and upper critical solution temperature is larger than $373.15 \mathrm{~K}$. There is only one two-liquid-phase-coexisting region in the triangle phase diagram of the system at 298.15 and $308.15 \mathrm{~K}$, as shown in Figs. 1 and 2, respectively. Note that the surfactant $\mathrm{C}_{4} \mathrm{E}_{1}$ mainly partitions into the lower aqueous phase and the composition of $\mathrm{C}_{4} \mathrm{E}_{1}$ is relatively small in the upper oil-rich phase. The fitting coefficients (both $R$ and $R^{2}$ ) of a linear expression to each tie line and its corresponding total composition data point are always better than 0.999 , as shown in Figs. 1 and 2.

When the temperature is increased above the lower critical solution temperature, $311.15 \mathrm{~K}$, the system should have a three-liquid-phase-coexisting region. As expected, Fig. 3 shows that the system at $318.15 \mathrm{~K}$ exhibits one three-liquid-phase-coexisting tie triangle and three two-liquid-phase-coexisting envelopes.

In addition, the temperature effect on the composition of the three-liquid-phase-coexisting region was examined. For the systems higher than $318.15 \mathrm{~K}$, only the compositions of three-liquid-phase-coexisting tie triangles were measured at every $5 \mathrm{~K}$ from 318.15 to $338.15 \mathrm{~K}$. The experimental results of the equilibrium compositions of the three-liquid-phase-coexisting tie triangle are

Table 2

Experimental and calculated mass fractions of equilibrium liquid phases for the ternary system water + tetradecane $+\mathrm{C}_{4} \mathrm{E}_{1}$ at $298.15 \mathrm{~K}$

\begin{tabular}{|c|c|c|c|c|c|c|c|}
\hline \multicolumn{4}{|c|}{ Experimental data } & \multicolumn{4}{|c|}{ Calculated results } \\
\hline \multicolumn{2}{|c|}{ Oil-rich phase } & \multicolumn{2}{|c|}{ Water-rich phase } & \multicolumn{2}{|c|}{ Oil-rich phase } & \multicolumn{2}{|c|}{ Water-rich phase } \\
\hline $\mathrm{H}_{2} \mathrm{O}$ & $\mathrm{C}_{4} \mathrm{E}_{1}$ & $\mathrm{H}_{2} \mathrm{O}$ & $\mathrm{C}_{4} \mathrm{E}_{1}$ & $\mathrm{H}_{2} \mathrm{O}$ & $\mathrm{C}_{4} \mathrm{E}_{1}$ & $\mathrm{H}_{2} \mathrm{O}$ & $\mathrm{C}_{4} \mathrm{E}_{1}$ \\
\hline 0.0002 & 0.0216 & 0.9276 & 0.0724 & 0.0016 & 0.0384 & 0.9432 & 0.0568 \\
\hline 0.0007 & 0.0428 & 0.8678 & 0.1322 & 0.0036 & 0.0674 & 0.8868 & 0.1132 \\
\hline 0.0008 & 0.0459 & 0.7762 & 0.2238 & 0.0049 & 0.0833 & 0.8005 & 0.1994 \\
\hline 0.0009 & 0.0464 & 0.6730 & 0.3227 & 0.0043 & 0.0759 & 0.6863 & 0.3133 \\
\hline 0.0009 & 0.0469 & 0.5523 & 0.4364 & 0.0037 & 0.0674 & 0.5660 & 0.4324 \\
\hline 0.0009 & 0.0472 & 0.4858 & 0.4987 & 0.0035 & 0.0660 & 0.4985 & 0.4980 \\
\hline 0.0010 & 0.0484 & 0.4247 & 0.5549 & 0.0036 & 0.0671 & 0.4374 & 0.5554 \\
\hline 0.0012 & 0.0517 & 0.3636 & 0.6082 & 0.0039 & 0.0714 & 0.3712 & 0.6139 \\
\hline 0.0014 & 0.0568 & 0.2788 & 0.6765 & 0.0048 & 0.0835 & 0.2845 & 0.6795 \\
\hline 0.0019 & 0.0667 & 0.2135 & 0.7252 & 0.0061 & 0.1026 & 0.2129 & 0.7156 \\
\hline 0.0033 & 0.1094 & 0.1301 & 0.7386 & 0.0093 & 0.1532 & 0.1240 & 0.7128 \\
\hline 0.0125 & 0.2272 & 0.0724 & 0.6438 & 0.0132 & 0.2262 & 0.0709 & 0.6532 \\
\hline \multicolumn{4}{|c|}{$\begin{array}{l}\text { Average error }=\sum_{i=1}^{N} \frac{\left|W_{i}^{\text {expt }}-W_{i}^{\text {calc }}\right|}{N}, \\
\quad \text { where } N \text { is the number of tie lines. }\end{array}$} & 0.003 & 0.02 & 0.01 & 0.01 \\
\hline
\end{tabular}


Table 3

Experimental and calculated mass fractions of equilibrium liquid phases for the ternary system water + tetradecane $+\mathrm{C}_{4} \mathrm{E}_{1}$ at $308.15 \mathrm{~K}$

\begin{tabular}{|c|c|c|c|c|c|c|c|}
\hline \multicolumn{4}{|c|}{ Experimental data } & \multicolumn{4}{|c|}{ Calculated results } \\
\hline \multicolumn{2}{|c|}{ Oil-rich phase } & \multicolumn{2}{|c|}{ Water-rich phase } & \multicolumn{2}{|c|}{ Oil-rich phase } & \multicolumn{2}{|c|}{ Water-rich phase } \\
\hline $\mathrm{H}_{2} \mathrm{O}$ & $\mathrm{C}_{4} \mathrm{E}_{1}$ & $\mathrm{H}_{2} \mathrm{O}$ & $\mathrm{C}_{4} \mathrm{E}_{1}$ & $\mathrm{H}_{2} \mathrm{O}$ & $\mathrm{C}_{4} \mathrm{E}_{1}$ & $\mathrm{H}_{2} \mathrm{O}$ & $\mathrm{C}_{4} \mathrm{E}_{1}$ \\
\hline 0.0007 & 0.0298 & 0.9322 & 0.0678 & 0.0003 & 0.0003 & 0.9075 & 0.0920 \\
\hline 0.0009 & 0.0598 & 0.8796 & 0.1204 & 0.0003 & 0.0005 & 0.8320 & 0.1671 \\
\hline 0.0012 & 0.0609 & 0.7923 & 0.2077 & 0.0003 & 0.0008 & 0.7494 & 0.2489 \\
\hline 0.0012 & 0.0610 & 0.6804 & 0.3136 & 0.0003 & 0.0014 & 0.6500 & 0.3463 \\
\hline 0.0012 & 0.0615 & 0.5566 & 0.4308 & 0.0003 & 0.0024 & 0.5417 & 0.4501 \\
\hline 0.0014 & 0.0616 & 0.4880 & 0.4947 & 0.0003 & 0.0036 & 0.4774 & 0.5096 \\
\hline 0.0015 & 0.0630 & 0.4288 & 0.5493 & 0.0003 & 0.0052 & 0.4195 & 0.5609 \\
\hline 0.0013 & 0.0645 & 0.3642 & 0.6067 & 0.0003 & 0.0083 & 0.3559 & 0.6138 \\
\hline 0.0016 & 0.0708 & 0.2801 & 0.6715 & 0.0004 & 0.0170 & 0.2721 & 0.6740 \\
\hline 0.0022 & 0.0819 & 0.2135 & 0.7131 & 0.0005 & 0.0345 & 0.2028 & 0.7094 \\
\hline 0.0050 & 0.1353 & 0.1290 & 0.7264 & 0.0012 & 0.0904 & 0.1226 & 0.7138 \\
\hline \multicolumn{4}{|c|}{$\begin{array}{c}\text { Average error }=\sum_{i=1}^{N} \frac{\left|W_{i}^{\text {expt }}-W_{i}^{\text {calc }}\right|}{N}, \\
\text { where } N \text { is the number of tie lines }\end{array}$} & 0.001 & 0.05 & 0.002 & 0.02 \\
\hline
\end{tabular}

Table 4

Experimental and calculated mass fractions of equilibrium liquid phases for the ternary system water + tetradecane $+\mathrm{C}_{4} \mathrm{E}_{1}$ at $318.15 \mathrm{~K}$

\begin{tabular}{|c|c|c|c|c|c|c|c|c|c|c|c|}
\hline \multicolumn{6}{|c|}{ Experimental data } & \multicolumn{6}{|c|}{ Calculated results } \\
\hline \multicolumn{2}{|c|}{ Oil-rich phase } & \multicolumn{2}{|c|}{ Surfactant-rich phase } & \multicolumn{2}{|c|}{ Water-rich phase } & \multicolumn{2}{|c|}{ Oil-rich phase } & \multicolumn{2}{|c|}{ Surfactant-rich phase } & \multicolumn{2}{|c|}{ Water-rich phase } \\
\hline $\mathrm{H}_{2} \mathrm{O}$ & $\mathrm{C}_{4} \mathrm{E}_{1}$ & $\mathrm{H}_{2} \mathrm{O}$ & $\mathrm{C}_{4} \mathrm{E}_{1}$ & $\mathrm{H}_{2} \mathrm{O}$ & $\mathrm{C}_{4} \mathrm{E}_{1}$ & $\mathrm{H}_{2} \mathrm{O}$ & $\mathrm{C}_{4} \mathrm{E}_{1}$ & $\mathrm{H}_{2} \mathrm{O}$ & $\mathrm{C}_{4} \mathrm{E}_{1}$ & $\mathrm{H}_{2} \mathrm{O}$ & $\mathrm{C}_{4} \mathrm{E}_{1}$ \\
\hline \multicolumn{12}{|c|}{ Three-liquid-phase coexisting } \\
\hline 0.0019 & 0.0812 & 0.4250 & 0.5510 & 0.8809 & 0.1191 & 0.4141 & 0.5671 & 0.4204 & 0.5651 & 0.8467 & 0.1531 \\
\hline \multicolumn{12}{|c|}{ Two-liquid-phase-coexisting region on the water/tetradecane side } \\
\hline 0.0006 & 0.0372 & & & 0.9419 & 0.0581 & 0.0018 & 0.0350 & & & 0.9397 & 0.0602 \\
\hline 0.0020 & 0.0793 & & & 0.8953 & 0.1047 & 0.0041 & 0.0627 & & & 0.8777 & 0.1222 \\
\hline \multicolumn{12}{|c|}{ Two-liquid-phase coexisting region on the $\mathrm{C}_{4} \mathrm{E}_{1}$ /tetradecane side } \\
\hline 0.0025 & 0.0870 & 0.3409 & 0.6222 & & & 0.0056 & 0.0782 & 0.3379 & 0.6246 & & \\
\hline 0.0025 & 0.0947 & 0.2525 & 0.6862 & & & 0.0073 & 0.0971 & 0.2431 & 0.6739 & & \\
\hline 0.0048 & 0.1264 & 0.1666 & 0.7314 & & & 0.0112 & 0.1420 & 0.1480 & 0.6759 & & \\
\hline 0.0136 & 0.2296 & 0.1040 & 0.6770 & & & 0.0164 & 0.2111 & 0.0883 & 0.6252 & & \\
\hline \multicolumn{12}{|c|}{ Two-liquid-phase-coexisting region on the water/ $\mathrm{C}_{4} \mathrm{E}_{1}$ side } \\
\hline & & 0.4676 & 0.5202 & 0.8717 & 0.1283 & & & 0.4209 & 0.5630 & 0.8453 & 0.1546 \\
\hline $\begin{array}{l}\text { Average er } \\
\text { where } I\end{array}$ & $\begin{array}{l}=\sum_{i=1}^{N} \\
\text { the nun }\end{array}$ & $\frac{V_{i}^{\text {expt }}-1}{N}$ & & & & 0.003 & 0.01 & 0.01 & 0.03 & 0.02 & 0.02 \\
\hline
\end{tabular}

Table 5

Experimental mass fractions of equilibrium liquid phases of three-liquid-phase-coexisting tie triangles for the ternary system water + tetradecane $+\mathrm{C}_{4} \mathrm{E}_{1}$ from 318.15 to $338.15 \mathrm{~K}$

\begin{tabular}{|c|c|c|c|c|c|c|c|c|c|c|c|c|}
\hline \multirow[t]{3}{*}{$t\left({ }^{\circ} \mathrm{C}\right)$} & \multicolumn{6}{|c|}{ Experimental data } & \multicolumn{6}{|c|}{ Calculated results } \\
\hline & \multicolumn{2}{|c|}{ Oil-rich phase } & \multicolumn{2}{|c|}{$\mathrm{C}_{4} \mathrm{E}_{1}$-rich phase } & \multicolumn{2}{|c|}{ Water-rich phase } & \multicolumn{2}{|c|}{ Oil-rich phase } & \multicolumn{2}{|c|}{$\mathrm{C}_{4} \mathrm{E}_{1}$-rich phase } & \multicolumn{2}{|c|}{ Water-rich phase } \\
\hline & $\mathrm{H}_{2} \mathrm{O}$ & $\mathrm{C}_{4} \mathrm{E}_{1}$ & $\mathrm{H}_{2} \mathrm{O}$ & $\mathrm{C}_{4} \mathrm{E}_{1}$ & $\mathrm{H}_{2} \mathrm{O}$ & $\mathrm{C}_{4} \mathrm{E}_{1}$ & $\mathrm{H}_{2} \mathrm{O}$ & $\mathrm{C}_{4} \mathrm{E}_{1}$ & $\mathrm{H}_{2} \mathrm{O}$ & $\mathrm{C}_{4} \mathrm{E}_{1}$ & $\mathrm{H}_{2} \mathrm{O}$ & $\mathrm{C}_{4} \mathrm{E}_{1}$ \\
\hline 45 & 0.0019 & 0.0812 & 0.4250 & 0.5510 & 0.8809 & 0.1191 & 0.0052 & 0.0652 & 0.4204 & 0.5651 & 0.8600 & 0.1399 \\
\hline 50 & 0.0024 & 0.0973 & 0.3541 & 0.6084 & 0.8970 & 0.1030 & 0.0060 & 0.0956 & 0.3519 & 0.6112 & 0.8972 & 0.1028 \\
\hline 55 & 0.0030 & 0.1097 & 0.3241 & 0.6298 & 0.9063 & 0.0937 & 0.0062 & 0.1102 & 0.3089 & 0.6477 & 0.9128 & 0.0872 \\
\hline 60 & 0.0045 & 0.1300 & 0.2996 & 0.6455 & 0.9135 & 0.0865 & 0.0078 & 0.1296 & 0.2992 & 0.6538 & 0.9102 & 0.0898 \\
\hline 65 & 0.0052 & 0.1500 & 0.2859 & 0.6520 & 0.9163 & 0.0837 & 0.0086 & 0.1381 & 0.2905 & 0.6575 & 0.9089 & 0.0911 \\
\hline \multicolumn{7}{|c|}{$\begin{array}{l}\text { Average error }=\sum_{i=1}^{N} \frac{\left|W_{i}^{\text {expt }}-W_{i}^{\text {calc }}\right|}{N}, N \\
\quad \text { is the number of data points }\end{array}$} & 0.003 & 0.005 & 0.007 & 0.010 & 0.010 & 0.010 \\
\hline
\end{tabular}




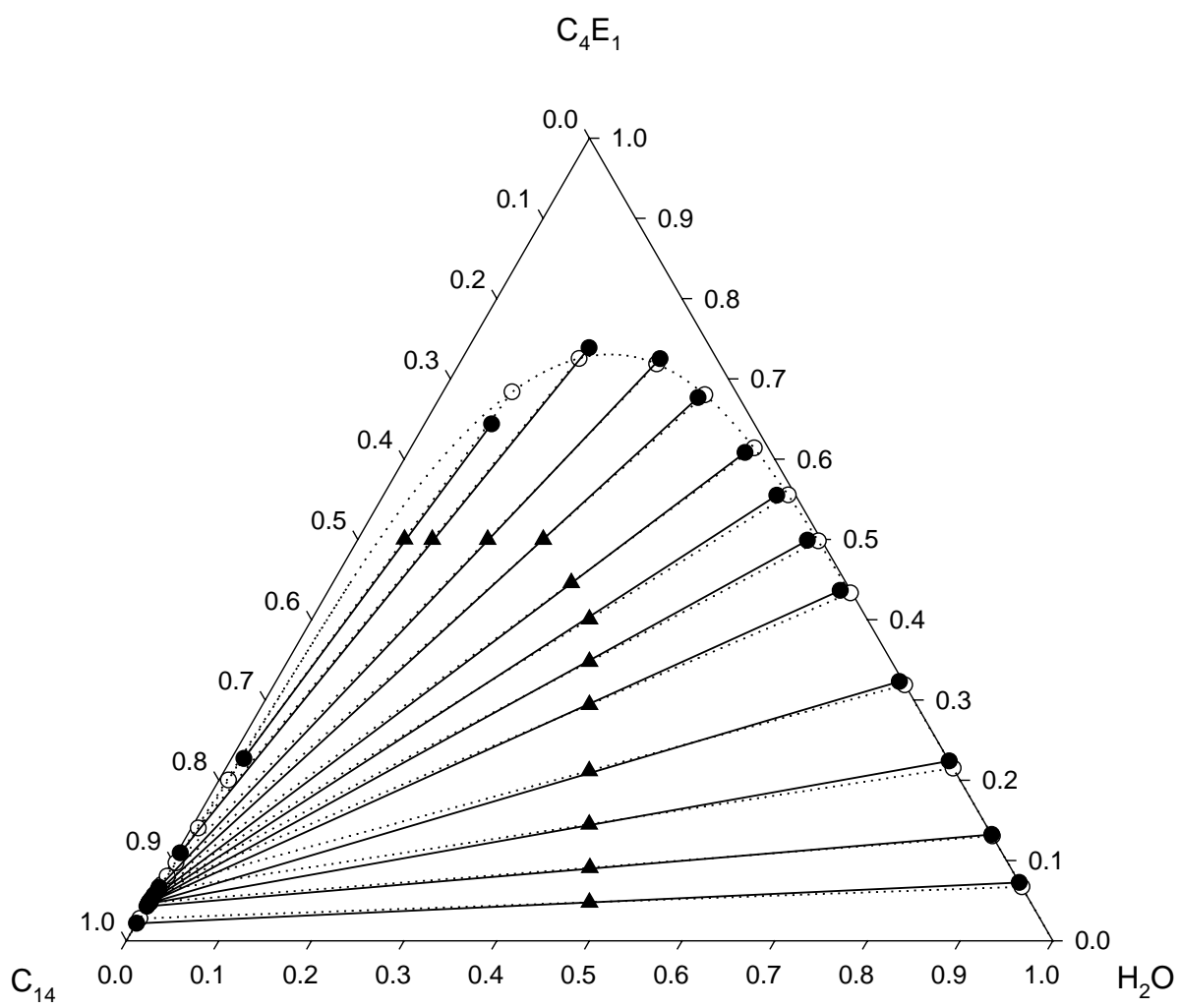

Fig. 1. Ternary liquid-liquid equilibria (mass fraction) for the system water + tetradecane $+\mathrm{C}_{4} \mathrm{E}_{1}$ at $298.15 \mathrm{~K}$ : experimental tie lines $((\mathbf{O})$ solid line); calculated binodal curve (dotted curve) and tie lines $((\bigcirc)$ dotted line); total compositions $(\mathbf{\Delta})$.

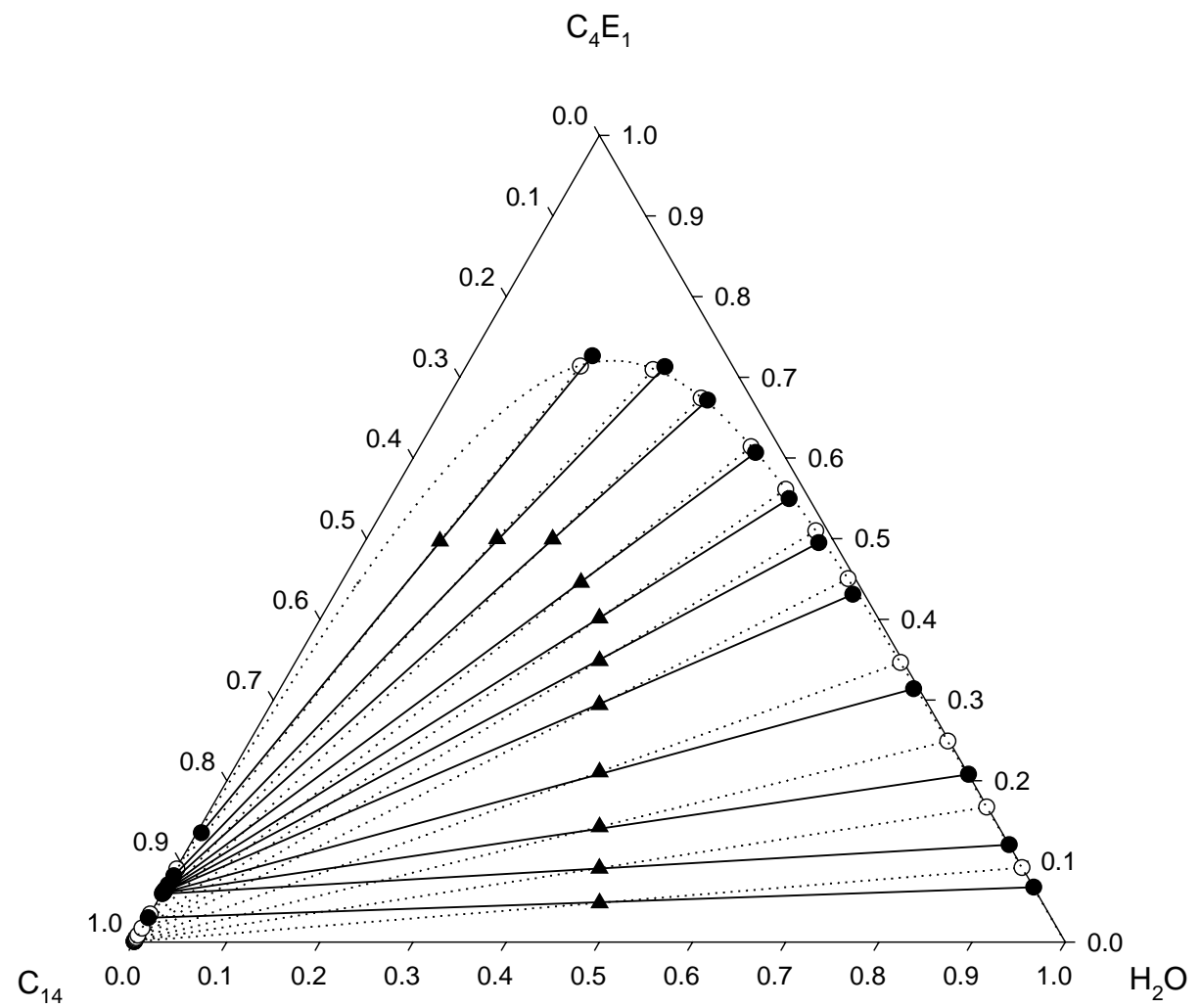

Fig. 2. Ternary liquid-liquid equilibria (mass fraction) for the system water + tetradecane $+\mathrm{C}_{4} \mathrm{E}_{1}$ at $308.15 \mathrm{~K}$ : experimental tie lines $(($ solid line); calculated binodal curve (dotted curve) and tie lines $((\bigcirc)$ dotted line); total compositions 


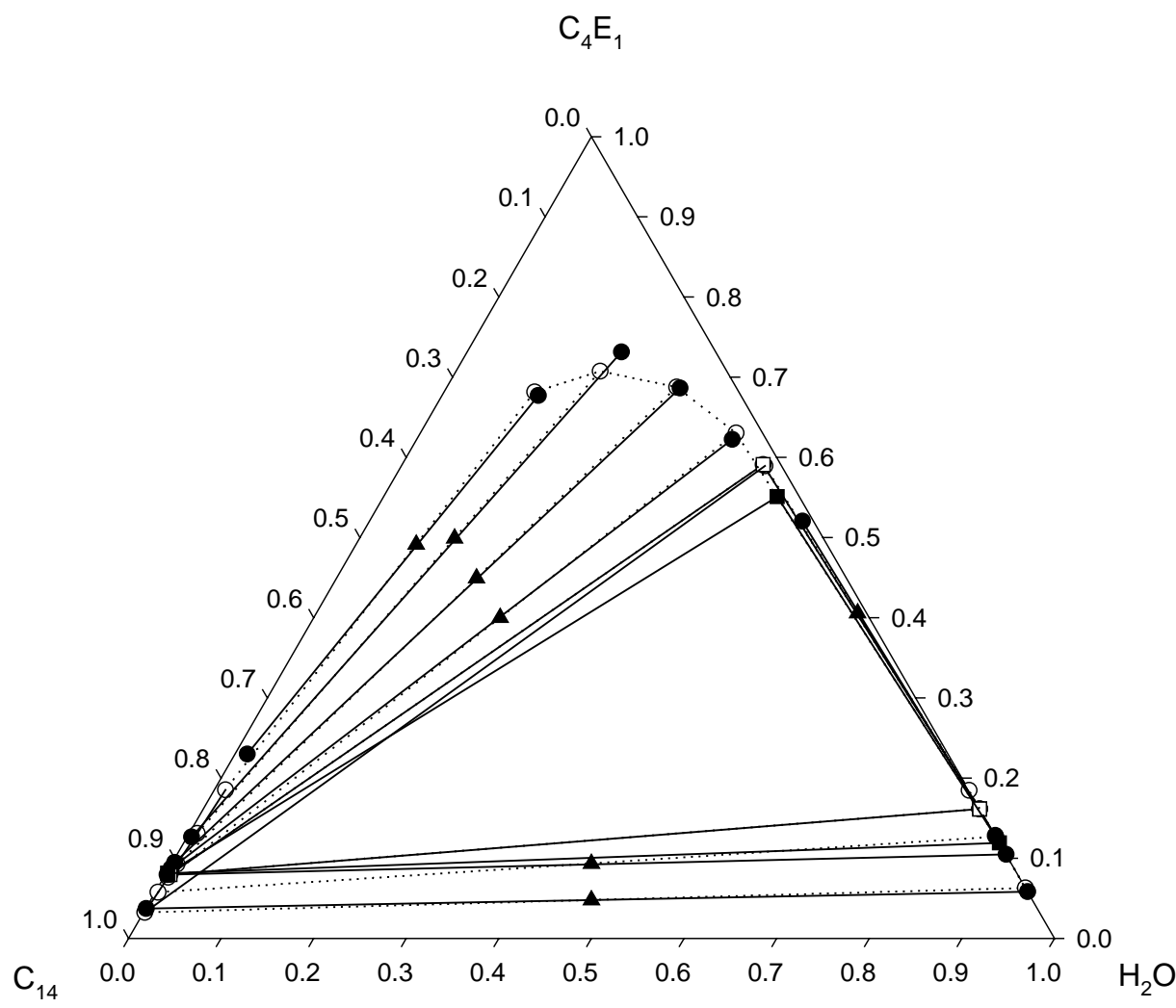

Fig. 3. Ternary liquid-liquid equilibria (mass fraction) for the system water + tetradecane $+\mathrm{C}_{4} \mathrm{E}_{1}$ at $318.15 \mathrm{~K}$ : experimental tie lines $((\mathbf{O})$ solid line); calculated binodal curves (dotted curve) and tie line $((\bigcirc)$ dotted line); total compositions $(\boldsymbol{\Delta})$; experimental three-liquid-phase-coexisting tie triangle $(\boldsymbol{\square}$ solid line); calculated three-liquid-phase-coexisting tie triangle $(\square)$ dotted line).

listed in Table 5. It is obvious that the apex of the three-liquid-phase-coexisting tie triangle, i.e. the $\mathrm{C}_{4} \mathrm{E}_{1}$-rich phase, shifts counterclockwise with an increase in temperature, as shown in Fig. 4, consistent with the observation of Kahlweit and Strey [18]. Note that the surfactant moves continuously from the water-rich phase to the oil-rich phase along with increasing temperature, as shown in Table 5.

The UNIQUAC model of Abrams and Prausnitz [17] was used to correlate the experimental data. In this study, the relative van der Waals volume $r_{i}$ and van der Waals surface area $q_{i}$ were adopted from the UNIFAC group contribution of Hansen et al. [19], listed in Table 4. The effective binary interaction parameter, $a_{i j}$, is defined by

$a_{i j}=\frac{u_{i j}-u_{j j}}{R}$

where $R$ is the gas constant, and $u_{i j}$ is the UNIQUAC interaction parameter between molecules $i$ and $j$.

There are two effective binary interaction parameters for a pair of substances. Therefore, six effective binary interaction parameters are required for a ternary system. For the system at 298.15 and $315.15 \mathrm{~K}$, there is only one two-liquid-phase-coexisting region. These six effective binary interaction parameters were determined by numerically minimizing the following objective function [20]:

$$
F_{x}=\sum_{k=1}^{N} \sum_{j=1}^{2} \sum_{i=1}^{3}\left(\frac{x_{i j k}^{\mathrm{expl}}-x_{i j k}^{\mathrm{calc}}}{x_{i j k}^{\mathrm{expl}}}\right)^{2},
$$

where $x_{i j k}^{\text {expl }}$ and $x_{i j k}^{\text {calc }}$ are the experimental and calculated mole fraction, respectively, of component $i$ in phase $j$ along a tie line $k$. The liquid-liquid equilibrium flash calculation [21] was applied to evaluate the compositions of both liquid phases along each tie line by using the experimental total compositions as input data. As one can see in Figs. 1 and 2 , the predicted binodal curve was in a very good agreement with the experimental result. The UNIQUAC model describes the experimental data well except at regions close to the plait point, especially as shown in Fig. 1.

On the other hand, for the systems at $318.15 \mathrm{~K}$ and higher temperatures, there are one three-liquid-phase-coexisting tie triangle and three two-liquid-phase-coexisting envelopes in each triangle phase diagram. Sassen et al. [22] pointed out that it is not clear whether the UNIQUAC model is able to predict a three-liquid-phase-coexisting region of the ternary system water + dodecane $+\mathrm{C}_{7} \mathrm{E}_{5}$. In our previous study $[14,15]$, we also had the same problem of correlating the experimental data of the three-liquid-phase-coexisting tie triangle to the UNIQUAC model. However, Negahban et al. [23] and Brandani et al. [24] were able to use the 


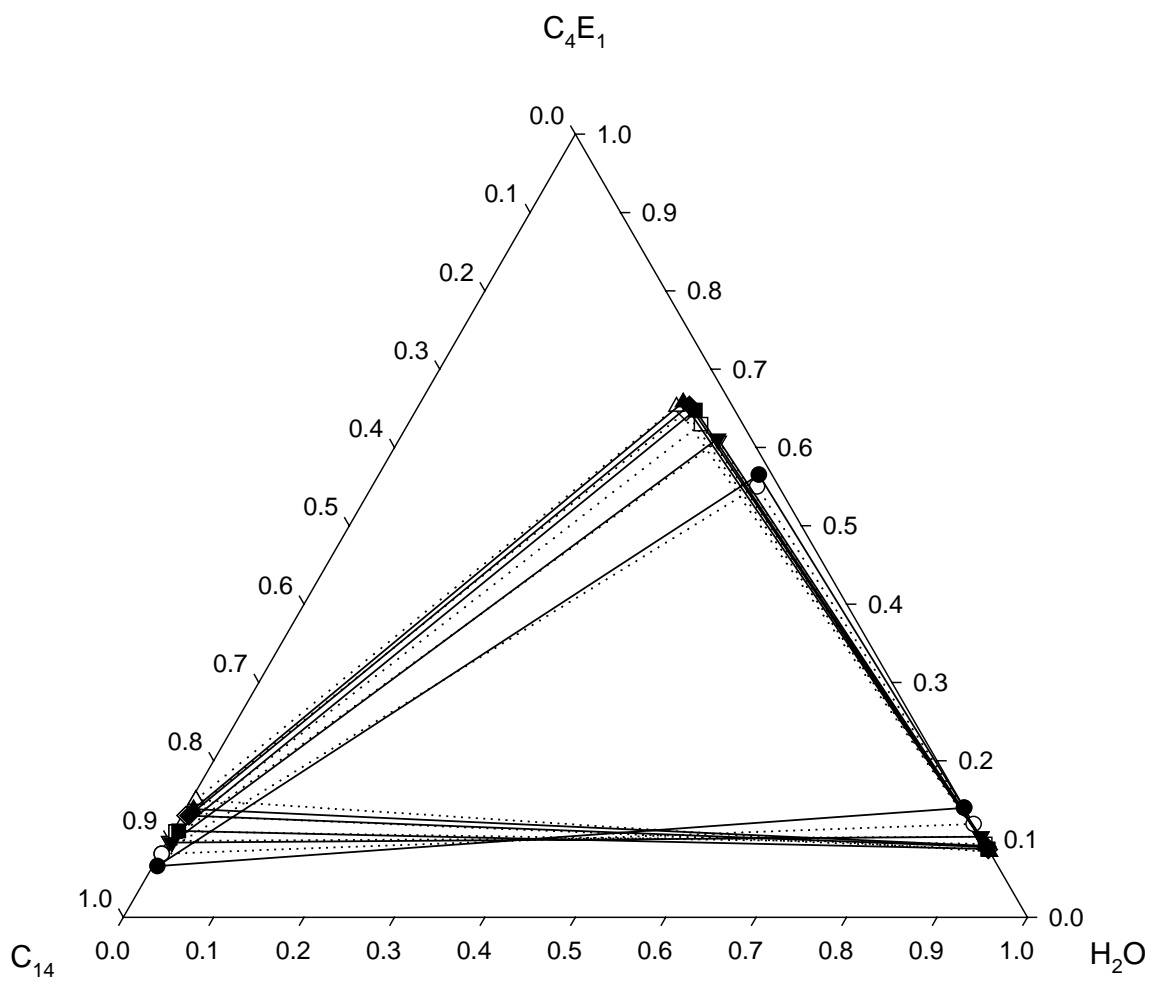

Fig. 4. Variation of the liquid-liquid equilibria (mass fraction) of three-liquid-phase coexisting tie triangle for the system water + tetradecane $+\mathrm{C}_{4} \mathrm{E}_{1}$ as a function of temperature ranging from 318.15 to $338.15 \mathrm{~K}$ : experimental three-liquid-phase-coexisting tie triangle $((\mathbf{O}) 318.15 \mathrm{~K} ;(\boldsymbol{\nabla}) 323.15 \mathrm{~K} ;(\boldsymbol{\square})$ $328.15 \mathrm{~K} ;(\diamond) 333.15 \mathrm{~K} ;(\boldsymbol{\Delta}) 338.15 \mathrm{~K}$; solid symbol and solid line); calculated three-liquid-phase-coexisting tie triangle $((\bigcirc) 318.15 \mathrm{~K} ;(\nabla) 323.15 \mathrm{~K}$; $(\square) 328.15 \mathrm{~K} ;(\diamond) 333.15 \mathrm{~K} ;(\triangle) 338.15 \mathrm{~K}$, open symbol and dotted line).

UNIQUAC model to describe the ternary system water + decane $+\mathrm{C}_{4} \mathrm{E}_{1}$ successfully. It should be pointed out that in these studies $[23,24]$, both the van der Waals volume $r_{i}$ and the van der Waals surface area $q_{i}$ of $\mathrm{C}_{4} \mathrm{E}_{1}$ were chosen as adjustable parameters in the regression procedure. It is interesting to note that their regression results $\left(r_{\mathrm{C}_{4} \mathrm{E}_{1}}=4.4093\right.$ and $\left.q_{\mathrm{C}_{4} \mathrm{E}_{1}}=5.8724\right)$ are substantially different from that of Hansen et al. [19] (listed in Table 6, $r_{\mathrm{C}_{4} \mathrm{E}_{1}}=5.0558$ and $q_{\mathrm{C}_{4} \mathrm{E}_{1}}=4.3720$ ). In this study, both the volume parameter and the surface area parameter of $\mathrm{C}_{4} \mathrm{E}_{1}$ were directly taken from Hansen et al. [19] and fixed as constants in the regression procedure.

As we mentioned above, the systems at $318.15 \mathrm{~K}$ and higher temperatures exhibit one three-liquid-phase-coexisting tie triangle and three two-liquid-phase-coexisting envelopes. There are two obvious ways to correlate the experimental data to the UNIQUAC model. The six ef-

Table 6

The relative van der Waals volume $r$ and van der Waals surface area $q$ [19]

\begin{tabular}{lll}
\hline Compound & $r$ & $q$ \\
\hline Water & 0.9200 & 1.4000 \\
2-Butyloxyethanol & 5.0558 & 4.3720 \\
Tetradecane & 9.8948 & 8.1400 \\
\hline
\end{tabular}

fective binary interaction parameters can be determined by the numerical regression of either only three-phase tie triangle or all available data including the three-phase tie triangle and three two-phase envelopes. According to Negahban et al. [25], the effective UNIQUAC binary interaction parameters determined from the correlation of only three-liquid-phase-coexisting data describe the entire phase equilibria satisfactorily. In addition, the deviation of the experimental data and the predicted results based on the interaction parameters determined from the correlation of only three-liquid-phase-coexisting data is slightly worse than that of all available data [25]. Therefore, in this study only the compositions of the three-liquid-phase-coexisting tie triangle were used to determine the six effective binary interaction parameters for the systems at $318.15 \mathrm{~K}$ and higher temperatures by numerically minimizing the following objective function $[20,23,25]$ :

$$
F_{x}=\sum_{j=1}^{3} \sum_{i=1}^{3}\left(\frac{x_{i j}^{\text {expl }}-x_{i j}^{\text {calc }}}{x_{i j}^{\text {expl }}}\right)^{2},
$$

where $x_{i j}^{\text {expl }}$ and $x_{i j}^{\text {calc }}$ are the experimental and calculated mole fraction, respectively, of component $i$ in phase $j$ of a three-liquid-phase-coexisting tie triangle. Note that the experimental results of three two-liquid-phase-coexisting 
Table 7

The effective UNIQUAC interaction parameters for the system water (1) $+\mathrm{C}_{4} \mathrm{E}_{1}(2)+$ tetradecane (3)

\begin{tabular}{lllllll}
\hline$t(\mathrm{~K})$ & $a_{12}$ & $a_{21}$ & $a_{13}$ & $a_{31}$ & $a_{23}$ & $a_{32}$ \\
\hline 298.15 & 229.3 & -106.2 & 130.6 & 1602 & -35.67 & 153.6 \\
308.15 & 195.0 & -68.78 & 259.2 & 1916 & -111.9 & 255.2 \\
318.15 & 356.1 & -155.3 & 370.6 & 1742 & -92.25 & 216.9 \\
323.15 & 408.8 & -186.3 & 360.1 & 1983 & -221.4 & 464.0 \\
328.15 & 424.0 & -195.0 & 344.2 & 1984 & -227.2 & 477.6 \\
333.15 & 418.7 & -191.8 & 348.0 & 1983 & -225.9 & 472.3 \\
338.15 & 419.0 & -191.6 & 348.1 & 1983 & -226.5 & 472.5 \\
\hline
\end{tabular}

regions were not used to correlate the interaction parameters. Once all the six effective binary interaction parameters were determined, the liquid-liquid equilibrium flash calculation [24] was applied to directly predict the compositions of both liquid phases along each tie line in all three two-liquid-phase-coexisting envelopes by using the experimental total compositions as input data. As one can see in Fig. 3, the predicted binodal curves were consistent with the experimental results.

The subroutine DUMPOL of the IMSL library [26] was used to minimize the objective function $F_{x}$, Eqs. (2) and (3), and regression results of the UNIQUAC effective binary interaction parameters are shown in Table 7 . The calculated results for each tie line are given in Tables 2-5 to make a comparison with experimental data. The calculated binodal curves are also presented by dotted curves in Figs. 1-3. As one can see in Figs. 1-3, the phase behavior of the system water + dodecane $+\mathrm{C}_{4} \mathrm{E}_{1}$ is successfully described by the UNIQUAC model. Note that variation of the effective UNIQUAC interaction parameters is not a smooth function of temperature. The exact reason for this behavior is not clear. Currently, we are in the process of further examining this problem systematically.

\section{List of symbols}

$a_{i j} \quad$ effective UNIQUAC interaction parameter between species $i$ and $j$

$F_{x} \quad$ objective function

$N \quad$ number of tie-lines

$q \quad$ van der Waals surface area parameter

$R \quad$ gas constant

$r \quad$ van der Waals volume parameter

$u \quad$ UNIQUAC interaction parameter

$x \quad$ mole fraction

\section{Greek symbol}

$\tau_{i j} \quad$ UNIQUAC adjustable parameter

\section{Acknowledgements}

This work was supported by the Chinese Petroleum Company and the National Science Council of Taiwan, Republic of China.

\section{References}

[1] P.D. Fleming III, J.E. Vinatieri, The role of critical phenomena in oil recovery systems employing surfactants, J. Colloid Interface Sci. 81 (1981) 319-331.

[2] N.D. Gullickson, J.F. Scamehorn, J.H. Harwell, Surfactant-based separation processes, in: J.F. Scamehorn, J.F. Harwell (Eds.), Surfactant Science Series, vol. 33, Marcel Dekker, New York, 1989 (Chapter 6).

[3] H. Kunieda, S.E. Friberg, Critical phenomena in a surfactant/water/oil system. Basic study on the correlation between solubilization, microemulsion, and ultralow interfacial tensions, Bull. Chem. Soc. Jpn. 54 (1981) 1010-1014.

[4] L.-J. Chen, W.-J. Yan, Novel interfacial phenomena at liquid-liquid interfaces of the three-component surfactant system water $+n$-tetradecane $+\mathrm{C}_{6} \mathrm{E}_{2}$, J. Chem. Phys. 98 (1993) 4830-4837.

[5] M.-C. Yeh, L.-J. Chen, Wetting transitions at the air-liquid interface of water + tetradecane $+\mathrm{C}_{6} \mathrm{E}_{2}$ mixtures, J. Chem. Phys. 115 (2001) $8575-8582$.

[6] L.-J. Chen, W.-J. Yan, M.-C. Hsu, D.-L. Tyan, Wetting transitions at liquid-liquid interfaces in three-component water + oil + nonionic surfactant systems, J. Phys. Chem. 98 (8) (1994) 1910-1917.

[7] L.-J. Chen, S.-Y. Lin, J.-W. Xyu, Wetting/nonwetting behaviors in a ternary amphiphilic system, J. Chem. Phys. 104 (1996) 225-232.

[8] L.-J. Chen, C.-D. Chiu, F.-S. Shau, W.-J. Cheng, J.-G. Wu, Oil chain length effect on wetting transitions in ternary water + oil + surfactant mixtures, J. Phys. Chem. B 106 (2002) 12782-12786.

[9] M. Kahlweit, G. Busse, J. Winkler, Electric conductivity in microemulsions, J. Chem. Phys. 99 (1993) 5605-5614.

[10] H.-H. Lai, L.-J. Chen, Liquid-liquid equilibrium phase diagram and density of three water + nonionic surfactant $\mathrm{C}_{i} \mathrm{E}_{j}$ binary systems, J. Chem. Eng. Data 44 (1999) 251-253.

[11] B.-J. Lin, L.-J. Chen, Liquid-liquid equilibrium for the ternary system water + docecane + diethylene glycol monobutyl ether, J. Chem. Eng. Data 47 (2002) 992-996.

[12] Y.-L. Liu, D.-R. Chiou, L.-J. Chen, Liquid-liquid equilibrium for the ternary system water + octane + didthylene glycol monobutyl ether, J. Chem. Eng. Data 47 (2002) 310-312.

[13] Y.-L. Liu, B.-J. Lin, L.-J. Chen, Liquid-liquid equilibria for the ternary system water + decane + diethylene glycol monobutyl ether at 20,30, and $40{ }^{\circ} \mathrm{C}$, J. Chem. Eng. 48 (2003) 333-336.

[14] H. Hu, C.-D. Chiu, L.-J. Chen, Liquid-liquid equilibria for the ternary system water $+n$-dodecane $+2-(2-n$-hexyloxyethoxy)ethanol, Fluid Phase Equilibria 164 (1999) 187-194.

[15] H. Hu, L.-J. Chen, Liquid-liquid equilibria for the ternary system water $+n$-tetradecane $+2-(2-n$-hexyloxyethoxy)ethanol at 293.15 and 303.15 K, J. Chem. Eng. Data 45 (2000) 304-307.

[16] P.K. Kilpatrick, C.A. Gorman, H.T. Davis, L.E. Scriven, W.G.. Miller, Patterns of phase behavior in ternary ethoxylated alcohol- $n$ alkane-water mixtures, J. Phys. Chem. 90 (1986) 5292-5299.

[17] D.S. Abrams, J.M. Prausnitz, Statistical thermodynamics of liquid mixtures: A new expression for the excess Gibbs energy of partly or completely miscible systems, AIChE J. 21 (1975) 116-128.

[18] M. Kahlweit, R. Strey, Phase behavior of ternary systems of the type $\mathrm{H}_{2} \mathrm{O}$-oil-nonionic amphiphile (microemulsions), Angew. Chem. Int. Ed. Engl. 24 (1985) 654-668.

[19] H.K. Hansen, B. Coto, B. Kuhlmann, UNIFAC with linear temperature-dependent group-interaction parameters, in: IVC-SEP, Phase Equilibria and Separation Processes, SEP 9212, May, 1992, Danmarks Techniske Universitet, Danmark.

[20] F. García-Sánchez, J. Schwartzentruber, M.N. Ammar, H. Renon, Modeling of multiphase liquid equilibria for multicomponent mixtures, Fluid phase equilibria 121 (1996) 207-225.

[21] M.N. Ammar, H. Renon, The isothermal flash problem: new methods for phase split calculations, AIChE J. 33 (1987) 926-939.

[22] C.L. Sassen, A. Gonzales Casielles, Th.W. de Loos, J. de Swaan Arons, The influence of pressure and temperature on the phase 
behaviour of the system $\mathrm{H}_{2} \mathrm{O}+\mathrm{C}_{12}+\mathrm{C}_{7} \mathrm{E}_{5}$ and relevant binary subsystems, Fluid Phase Equilibria 72 (1992) 173-187.

[23] S. Negahban, G.P. Willhite, S.M. Walas, M.J. Michnick, Three-liquid-phase equilibria of ternary and quaternary mixtures, Fluid Phase Equilibria 32 (1986) 49-61.

[24] S. Brandani, V. Brandani, G. Del Re, G.D. Giacomo, Liquid-liquid equilibria of the ternary system water/2-butyloxyethanol/n-decane at three different temperatures, Fluid Phase Equlibria 94 (1994) 313 320.

[25] S. Negahban, G.P. Willhite, S.M. Walas, Modeling of three-phase liquid/liquid equilibria, SPE Reservoir Eng. 7 (1988) 10171024.

[26] IMSL Math/Library FORTRAN Subroutines for Mathematical Applications, IMSL, Inc., Houston, 1991 (Chapter 8). 